\title{
ASO Author Reflections: Stage 4 Laryngeal Cancer Rising in the United States
}

\author{
Michael M. Li, MD, and Stephen Y. Kang, MD \\ Department of Otolaryngology-Head and Neck Surgery, The Ohio State University Wexner Medical Center, Columbus, \\ $\mathrm{OH}$
}

\section{PAST}

Survival of patients with laryngeal cancer declined from 1985 to 2001, concurrent with the period during which organ preservation protocols were developed. 'Significant controversy arose regarding the driving force of this decline, and it remains unknown whether this downward trend in survival has continued into the current era.

\section{PRESENT}

Survival of patients with laryngeal cancer in the United States from 2004 to 2016 showed no significant change in 2- or 5-year observed survival (range, 54.3-56.5\%). ${ }^{2}$ Despite the lack of change in survival, upward stage migration occurred with each increasing year, conferring an additional risk of $2.2 \%$ for stage 4 disease. This was driven in large part by a $4.7 \%$ yearly increase in $\mathrm{N} 2$ disease, and to smaller degrees by $1.2 \%$ annual increases in $\mathrm{T} 3$ and $\mathrm{T} 4$ disease. The strongest demographic association with stage 4 disease was black race.

\section{FUTURE}

Although survival of patients with laryngeal cancer is no longer declining, modern treatment and technologic advances have not translated to improved survival. These advances may be negated by stage migration toward an increasing proportion of stage 4 disease. Black race was identified as strongly associated with stage 4 disease, and previous findings have shown black race to be associated also with worse outcomes in other cancers. ${ }^{3}$ Efforts should be directed toward early detection and timely treatment of laryngeal cancer to obtain incremental improvements in survival commensurate with the advances in laryngeal cancer treatment protocols.

DISCLOSURE There are no conflicts of interest.

\section{REFERENCES}

1. Forastiere AA, Maor M, Weber RS, et al. Long-term results of Intergroup RTOG 91-11: a phase III trial to preserve the larynxinduction cisplatin/5-FU and radiation therapy versus concurrent cisplatin and radiation therapy versus radiation therapy. J Clin Oncol. 2006;24(18 Suppl):5517. https://doi.org/10.1200/jco.2006. 24.18_suppl.5517.

2. Li M, Zhao S, Eskander A, et al. Stage migration and survival trends in laryngeal cancer. Ann Surg Oncol. 2021. https://doi.org/ 10.1245/s10434-021-10318-1.

3. Wasif N, Etzioni D, Habermann EB, et al. Racial and socioeconomic differences in the use of high-volume commission on cancer-accredited hospitals for cancer surgery in the United States. Ann Surg Oncol. 2018;25:1116-25. https://doi.org/10.1245/s1043 4-018-6374-0.

Publisher's Note Springer Nature remains neutral with regard to jurisdictional claims in published maps and institutional affiliations.

(C) Society of Surgical Oncology 2021

First Received: 26 May 2021

Accepted: 27 May 2021;

Published Online: 15 July 2021

S. Y. Kang, MD

e-mail: stephen.kang@osumc.edu 